Article

\title{
Competing Deformation Mechanisms in Periclase: Implications for Lower Mantle Anisotropy
}

\author{
Feng Lin ${ }^{1, *}$, Samantha Couper ${ }^{1}$, Mike Jugle ${ }^{2}$ and Lowell Miyagi ${ }^{1}$ \\ 1 Department of Geology and Geophysics, University of Utah, Salt Lake City, UT 84112, USA; \\ samantha.couper@utah.edu (S.C.); lowell.miyagi@utah.edu (L.M.) \\ 2 Kansas Water Resource Center, United States Geological Survey, 1204 Canterbury Dr, Hays, KS 67601, USA; \\ mjugle@usgs.gov \\ * Correspondence: feng.lin@utah.edu; Tel.: +01-801-581-7062
}

Received: 1 September 2019; Accepted: 22 October 2019; Published: 23 October 2019

check for updates

\begin{abstract}
Seismic anisotropy is observed above the core-mantle boundary in regions of slab subduction and near the margins of Large Low Shear Velocity Provinces (LLSVPs). Ferropericlase is believed to be the second most abundant phase in the lower mantle. As it is rheologically weak, it may be a dominant source for anisotropy in the lowermost mantle. Understanding deformation mechanisms in ferropericlase over a range of pressure and temperature conditions is crucial to interpret seismic anisotropy. The effect of temperature on deformation mechanisms of ferropericlase has been established, but the effects of pressure are still controversial. With the aim to clarify and quantify the effect of pressure on deformation mechanisms, we perform room temperature compression experiments on polycrystalline periclase to $50 \mathrm{GPa}$. Lattice strains and texture development are modeled using the Elasto-ViscoPlastic Self Consistent method (EVPSC). Based on modeling results, we find that $\{110\}\langle 1 \overline{1} 0\rangle$ slip is increasingly activated with higher pressure and is fully activated at 50 GPa. Pressure and temperature have a competing effect on activities of dominant slip systems. An increasing $\{100\}\langle 011\rangle:\{110\}\langle 1 \overline{1} 0\rangle$ ratio of slip activity is expected as material moves from cold subduction regions towards hot upwelling region adjacent to LLSVPs. This could explain observed seismic anisotropy in the circum-Pacific region that appears to weaken near margins of LLVSPs.
\end{abstract}

Keywords: periclase; deformation; high pressure; texture; plasticity modeling; anisotropy; D"

\section{Introduction}

Shear wave splitting is widely used to document seismic anisotropy in the lower mantle. In the bulk of the lower mantle, there is no compelling evidence for the existence of widespread anisotropy (e.g., [1-4]). However, anisotropy is widely observed above the core-mantle boundary (CMB) near regions of slab subduction and adjacent to the borders of Large Low Shear Velocity Provinces (LLVSPs). Generally, shear wave splitting of $\mathrm{V}_{\mathrm{SH}}>\mathrm{V}_{\mathrm{SV}}$ is observed for ray paths that are approximately parallel to the CMB in the circum-Pacific regions (e.g., $[3,5,6])$. Decreased anisotropy is typically observed towards LLVSP boundaries and becomes vanishing small within the LLVSPs (e.g., [7-9]). It is generally assumed that observed anisotropy is the result of plastic deformation of mantle rocks by dislocation creep (e.g., [9-12]). Several experiments have been conducted to study deformation mechanism of bridgmanite (e.g., $[13,14])$, the most abundant phase of the lower mantle, and post-perovskite (e.g., $[10,11])$, which is believed to be the most abundant phase in colder regions of the $\mathrm{D}^{\prime \prime}$ layer just above the CMB. Studies using 2D and 3D flow field methods [15-18] generally conclude that post-perovskite is consistent with observed anisotropy in the $\mathrm{D}^{\prime \prime}$. Ferropericlase, which is the second most abundant phase of the lower mantle, is also likely to be important. Due to its rheological weakness, comparatively large amounts of strain may be accommodated by ferropericlase [19]. This 
combined with high single crystal elastic anisotropy [20,21] implies that ferropericlase is an important contributor to $\mathrm{D}^{\prime \prime}$ anisotropy. Thus, understanding the deformation mechanisms of the ferropericlase at $\mathrm{D}^{\prime \prime}$ conditions is of great importance for understanding sources of anisotropy in the lower mantle. Deformation mechanisms of periclase have been shown to vary at different pressure and temperature conditions (e.g., [22]). Generating D" pressure and temperature conditions in deformation experiments is challenging and is not currently achievable. However, it is feasible to reach high pressure at low temperature or high temperature at low pressure, which gives the opportunity to separately study temperature and pressure effects on deformation mechanisms. Temperature effects on periclase deformation mechanisms have been well documented. Early experiments at low pressure inferred a dominant $\{110\}\langle 1 \overline{1} 0\rangle$ slip system at ambient conditions and an increase in activity of the $\{100\}\langle 011\rangle$ slip system with elevated temperature (e.g., [23-29]). However, pressure effects on deformation mechanisms are still controversial. Recent calculations on critical resolved shear stress (CRSS) of single crystal MgO predicted a transition to dominant $\{100\}\langle 011\rangle$ slip between $30 \mathrm{GPa}$ and $60 \mathrm{GPa}$ [30]. In contrast, earlier theoretical work showed dominant $\{110\}\langle 1 \overline{10}\rangle$ slip up to $100 \mathrm{GPa}$ [31]. High pressure single crystal deformation experiments showed trends in slip system strengths consistent with a change in dominant slip system from $\{110\}\langle 1 \overline{1} 0\rangle$ to $\{100\}\langle 011\rangle$ at $23 \mathrm{GPa}$ and $1000 \mathrm{~K}$ [32].

The plasticity behavior of polycrystals can be quite different compared to single crystals due to intergranular stress and strain heterogeneity, crystallographic preferred orientation (texture), microstructure, and grain interaction. Typically, the deformation of single crystals is fulfilled by a single slip system while in polycrystals multiple slip systems tend to be active. In polycrystals, back stress induced due to grain boundary interactions may hinder dislocations and force multiple slip systems to be activated, causing tangling of dislocations and hardening. The activity of slip systems may also be hampered by an unfavorable Schmid factor, which describes how stress is resolved on a slip plane and direction. Constraints on compatibility may also force activation of geometrically necessary slip systems. Thus, it can be difficult to directly apply single crystal CRSS to deduce polycrystals' deformation behavior. Room temperature deformation experiments of polycrystalline ferropericlase and periclase have documented texture consistent with dominant $\{110\}\langle 1 \overline{1} 0\rangle$ slip $[25,33-35]$. Recent work on ferropericlase found a surprising increase in differential stresses at mid mantle pressures. It was suggested that this increase in flow stress may be due to a change in deformation mechanisms with increasing pressure [36]. This study did not document a significant change in texture evolution, and as such, the deformation mechanism responsible for the increase in flow stress was not identified. Furthermore, it is not clear from this study if the inferred change in deformation mechanism is related to Fe content or if it also occurs in Fe free samples. Resistive heated Diamond Anvil Cell (DAC) experiments on the same composition of ferropericlase as [36] shows evidence of comparable activation of both $\{110\}\langle 1 \overline{10}\rangle$ and $\{100\}\langle 011\rangle$ slip systems at $1400 \mathrm{~K}$ in a range of 30-60 GPa [37]. [37] suggested that $\{100\}$ is favored by both high temperature and pressure. However as $\{100\}\langle 011\rangle$ is strongly favored by high temperature [25], the increased activity of $\{100\}$ may be primarily due to temperature.

In order to quantify the effect of pressure on deformation mechanisms and to understand the role of Fe changes in deformation mechanisms, we performed two DAC compression experiments on polycrystalline periclase up to $50 \mathrm{GPa}$ at room temperature. Lattice strains and texture evolution at varying pressures are recorded using radial diffraction geometry and modeled as a function of slip system activities using the Elasto-ViscoPlastic Self Consistent method (EVPSC).

\section{Experiment and Methods}

\subsection{Experiment Details}

Starting material of ground MgO powder (Alfa Aesar, 99.95\% purity, stock\# 14684, lot\# J03Q037) was loaded in a boron-kapton gasket [38] with a $350 \mu \mathrm{m}$ diameter boron insert and a $50 \mu \mathrm{m}$ diameter sample chamber. A panoramic type diamond anvil cell with 300-micron culet diamond anvils was used to compress the sample to high pressure. Synchrotron X-ray diffraction in radial geometry was 
performed at beamline 12.2.2 of the Advanced Light Source (ALS) (Lawrence Berkeley National Lab, Berkeley, CA, USA) using an X-ray wavelength of $0.49594 \AA$. The sample detector distance and detector non-orthogonality were calibrated using a $\mathrm{CeO}_{2}$ standard. Diffraction images were recorded using a MAR345 detector and an exposure time of $240 \mathrm{~s}$.

\subsection{Experiment Data Analysis}

The stress state in DAC experiments can be decomposed into hydrostatic and non-hydrostatic components as:

$$
\sigma=\left[\begin{array}{ccc}
\sigma_{1} & 0 & 0 \\
0 & \sigma_{1} & 0 \\
0 & 0 & \sigma_{3}
\end{array}\right]=\left[\begin{array}{ccc}
\sigma_{p} & 0 & 0 \\
0 & \sigma_{p} & 0 \\
0 & 0 & \sigma_{p}
\end{array}\right]+\left[\begin{array}{ccc}
-\frac{t}{3} & 0 & 0 \\
0 & -\frac{t}{3} & 0 \\
0 & 0 & \frac{2 t}{3}
\end{array}\right]
$$

where $\sigma_{p}=\frac{2 \sigma_{1}+\sigma_{3}}{3}$ is the hydrostatic stress, and differential stress $t=\sigma_{3}-\sigma_{1}$ can be used to infer the flow stress of the sample, assuming plastic flow occurs in DAC. Due to the deviatoric stress imposed on the sample, the measured d-spacing (distance between lattice planes) is a function of the angle between the compression axis $\left(\sigma_{3}\right)$ and diffraction plane normal $\chi$, as described in Singh, 1993 [39]:

$$
d_{m}(h k l)=d_{p}(h k l)\left[1+\left(1-3 \cos ^{2} \chi\right) Q(h k l)\right]
$$

where $d_{p}$ is the d-spacing under hydrostatic stress. $Q(h k l)$ describes the shift in measured d-spacing $d_{m}(h k l)$ from hydrostatic $d_{p}(h k l)$ and can be used to represent average lattice strain for plane $(h k l)$ (Figure 1). Pressure is calculated using a 3rd Birch-Murnaghan equation of state for $\mathrm{MgO}$ from Zha et al. (2000) [40]. The differential stress $t$ can be estimated from the lattice strains using following relationship:

$$
t(h k l)=6 G Q(h k l)
$$

where $G$ is the shear modulus of the aggregates. Systematic intensity variation along the diffraction rings indicates texture (Figure 1). Diffraction images are analyzed for lattice strain and texture using the Rietveld method implemented in the Materials Analysis Using Diffraction (MAUD) software [41]. Refinement closely follows the method for DAC data as outlined in [42].

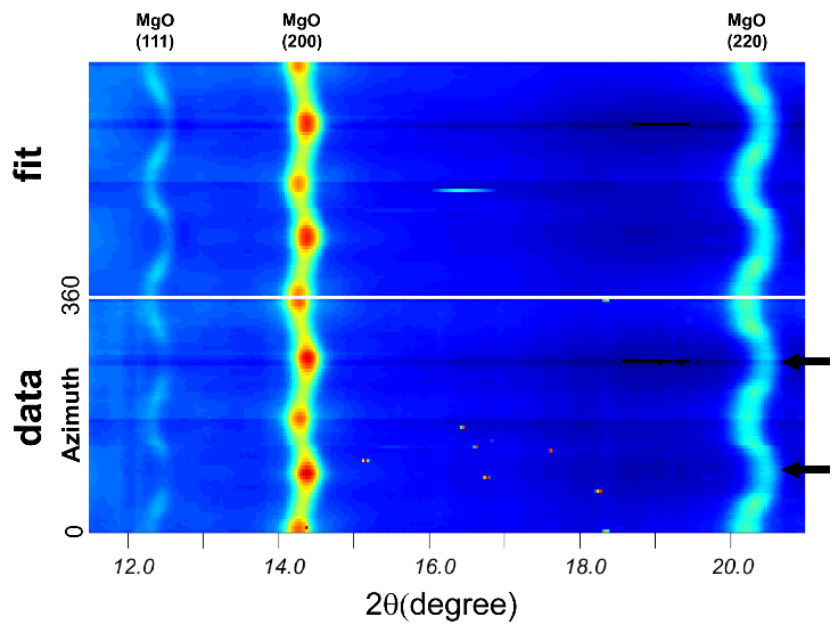

Figure 1. An unrolled diffraction image and MAUD fit of the MgO sample. Black arrow indicates the compression direction. Sinusoidal distortion of diffraction line indicates lattice strain. Systematic intensity variation along azimuth indicates texture.

\subsection{Plasticity Simulations}

Lattice strains and texture are modeled using the EVPSC method [43]. EVPSC is an effective medium self-consistent method, which considers individual grains as inclusions in a homogenous 
but anisotropic medium. The inclusions interact with the medium and the macroscopic properties are updated when the average strain and stress of all inclusion equals the macroscopic stress and strain at each deformation step. The plastic behavior of the inclusions is described by a rate-sensitive constitutive law on various slip systems:

$$
\dot{\varepsilon}_{i j}=\dot{\gamma}_{0} \sum_{s} m_{i j}^{s}\left\{\frac{\left|m_{k l}^{s} \sigma_{k l}\right|}{\tau^{s}}\right\}^{n} \operatorname{sgn}\left(m_{k l}^{s} \sigma_{k l}\right)
$$

where $\dot{\gamma}_{0}$ is the reference shear strain rate, $\tau^{S}$ is the rate sensitive critical resolved shear stress (CRSS) of a slip system $\mathbf{s}$ at the reference strain rate, $m_{k l}^{s}$ is the symmetric Schmid factor for the slip system $s, n$ is an empirical stress exponent, $\sigma_{k l}$ is the local stress tensor. When the stress resolved onto a given slip system is close to the threshold value $\tau^{\mathcal{S}}$, deformation will occur on the slip system. Since EVPSC does not explicitly account for complex grain to grain interactions and back-stress induced by misorientation of neighboring grains. These processes are accounted for in a "polycrystal CRSS" or effective CRSS. This effective CRSS is not equivalent to single crystal CRSS. The details of EVPSC simulation for high pressure deformation experiments can be found in [33].

\section{Results and Discussion}

The samples in both experiment runs are compressed up to $50 \mathrm{GPa}$. At pressure below $20 \mathrm{GPa}$, the lattice strains of $\{200\},\{220\}$, and $\{111\}$ plane are in an order of $Q(220)>Q(111)>Q(200)$. Above $20 \mathrm{GPa}, \mathrm{Q}(111)$, and $\mathrm{Q}(220)$ gradually increase. The slope of $\mathrm{Q}(111)$ is larger than $\mathrm{Q}(220)$ thus $\mathrm{Q}(111)$ surpasses $\mathrm{Q}(220)$ at $\sim 25 \mathrm{GPa}$ to $30 \mathrm{GPa}$, and the separation between $\mathrm{Q}(111)$ and $\mathrm{Q}(220)$ becomes larger with increasing pressure (Figure 2). Based on the previous results of EVPSC modeling for periclase [33], when the $\{110\}\langle 1 \overline{1} 0\rangle$ slip system is fully activated, the lattice strains are in an order of $Q(111)>Q(220)>Q(200)$. In contrast, an inverted order of $Q(200)>Q(220)>Q(111)$ occurs when $\{100\}\langle 011\rangle$ is fully activated. Activation of $\{100\}\langle 011\rangle$ slip decreases $Q(111)$ and increases $Q(200)$. Experimental lattice strains at high pressure above $30 \mathrm{GPa}$ resemble the case where $\{110\}\langle 1 \overline{10}\rangle$ is fully activated. Below $20 \mathrm{GPa}$, the lattice strains resemble Q-factor ordering consistent with mixed $\{110\}\langle 1 \overline{1} 0\rangle$ and $\{100\}\langle 011\rangle$ slip. Based on the previous modeling, a concentrated (100) compression texture indicates a high activity of $\{110\}\langle 1 \overline{1} 0\rangle$ slip, while a (110) texture indicates $\{100\}\langle 011\rangle$ slip [33]. In this study, periclase develops a concentrated (100) texture (Figure 3), due to high activity of the $\{110\}\langle 1 \overline{1} 0\rangle$ slip system. Given these experimental results, we suggest a deformation scenario in which $\{110\}\langle 1 \overline{10}\rangle$ and $\{100\}\langle 011\rangle$ slip systems are both activated at relatively low pressure below 20 GPa and $\{110\}\langle 1 \overline{10}\rangle$ become more active with increasing pressure.

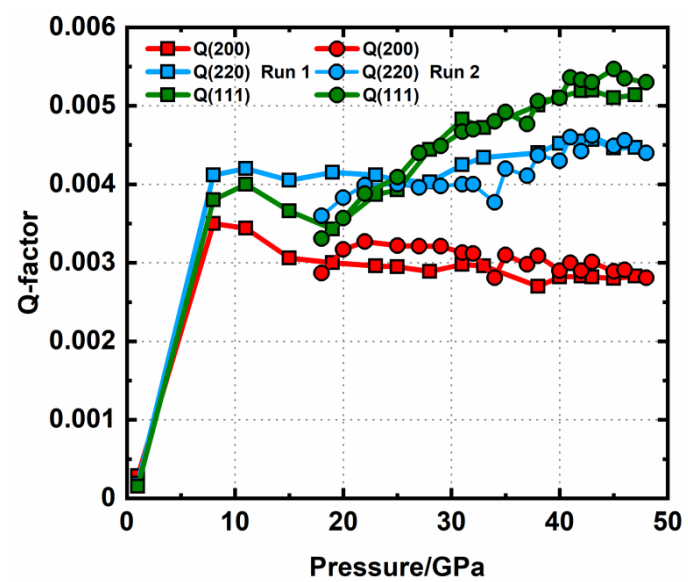

Figure 2. Experimental lattice strains of $\{200\},\{220\}$, and $\{111\}$ planes. Rectangles represent data in Run 1; circles represent data in Run 2. 


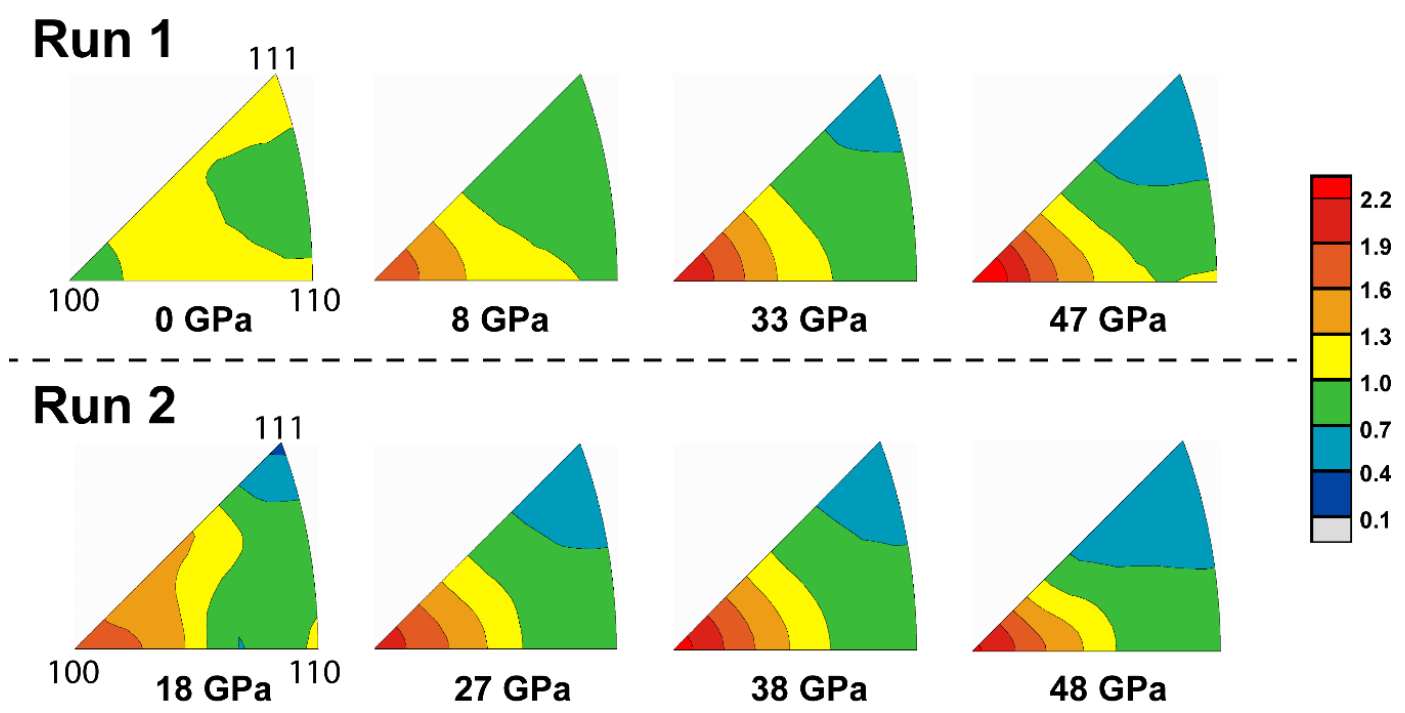

Figure 3. Inverse Pole Figures (IPFs) of the compression direction for periclase showing texture evolution with pressure. Scale bar is given in multiples of random distribution (m.r.d.).

In order to clarify and quantify this suggestion, we model the lattice strain and texture development in Run 1 using EVPSC method. The related modeling parameters are listed in Table 1 . A stress exponent of 8 is chosen for dislocation glide in a relatively rate-insensitive material. Theoretical calculations show that $\{111\}\langle 1 \overline{1} 0\rangle$ slip system is unlikely to activate at room temperature (e.g., [44]). Furthermore, activation of the $\{111\}\langle 1 \overline{1} 0\rangle$ system will give an intense (110) texture and Q-factors all with similar magnitudes [33]. Consequently, a very high CRSS is given to $\{111\}\langle 1 \overline{1} 0\rangle$ in order to fully suppress this system. Below $20 \mathrm{GPa}$, the CRSS of $\{110\}\langle 1 \overline{1} 0\rangle$ and $\{100\}\langle 011\rangle$ are set in order to match experimental lattice strains. In the experiments, we do not observe a decrease of all lattice strains. Thus, the increased activity of $\{110\}\langle 1 \overline{1} 0\rangle$ slip system is unlikely due to softening of $\{110\}\langle 1 \overline{1} 0\rangle$ but "pressure hardening" of $\{100\}\langle 011\rangle$ slip system. Single crystal CRSSs are not directly transferable to polycrystal behavior, since both "soft" and "hard" systems are activated as this is geometrically necessary to accommodate deformation of neighboring grains. However, the single crystal calculations [44] find that the CRSS of $\{100\}\langle 011\rangle$ starts to increase around $20 \mathrm{GPa}$ to $30 \mathrm{GPa}$. The calculated single crystal CRSS of $\{100\}\langle 011\rangle$ is close to the polycrystal magnitude (GPa) found here while single crystal CRSS for $\{110\}\langle 1 \overline{1} 0\rangle$ is much smaller. Thus, the pressure induced change in the single crystal CRSS of the harder $\{100\}\langle 011\rangle$ system may represent the general trend in the polycrystal. That is to say that because harder slip systems are geometrically necessary for polycrystal deformation, harder single crystal slip systems maybe more similar to polycrystal CRSS and more representative of the bulk strength of the polycrystal. In EVPSC, above $20 \mathrm{GPa}$, the activity of $\{100\}\langle 011\rangle$ is suppressed gradually by imposing a steep increase of CRSS with pressure (Table 1). The modeled lattice strains and texture provide a close match to the experiment (Figures 4 and 5). Below $20 \mathrm{GPa},\{110\}\langle 1 \overline{1} 0\rangle$ and $\{100\}\langle 011\rangle$ are activated in a ratio of 70:30. Above $20 \mathrm{GPa}$, due to the "pressure hardening" of the $\{100\}\langle 011\rangle$ slip system, the activity of $\{110\}\langle 1 \overline{1} 0\rangle$ gradually increases and reaches nearly $100 \%$ by $~ 50 \mathrm{GPa}$ (Figure 6). Q(111) surpasses Q(220) at $\sim 25 \mathrm{GPa}$, where $\{110\}\langle 1 \overline{1} 0\rangle$ and $\{100\}\langle 011\rangle$ are activated in a ratio of 80:20 (Figure 4; Figure 6). In the simulation, periclase develops a concentrated (100) texture (Figure 5) consistent with the experiment (Figure 3). 
Table 1. CRSSs value used in EVPSC. Values at 0 GPa are the initial CRSSs. A stress exponent of 8 is used for all slip systems.

\begin{tabular}{lccc}
\hline \multicolumn{1}{c}{ Pressure } & $\mathbf{0 ~ G P a}$ & $\mathbf{0 - 2 0 ~ G P a}$ & 20-50 GPa \\
Slip System & & & \\
\hline$\{110\}\langle 1 \overline{1} 0\rangle$ & $1.2 \mathrm{GPa}$ & $1.2 \mathrm{GPa}$ & $1.2 \mathrm{GPa}$ \\
$\{100\}\langle 011\rangle$ & $2.1 \mathrm{GPa}$ & $\mathrm{d}(\mathrm{CRSS}) / \mathrm{dP}=0.01$ & $\mathrm{~d}(\mathrm{CRSS}) / \mathrm{dP}=0.1$ \\
\hline
\end{tabular}

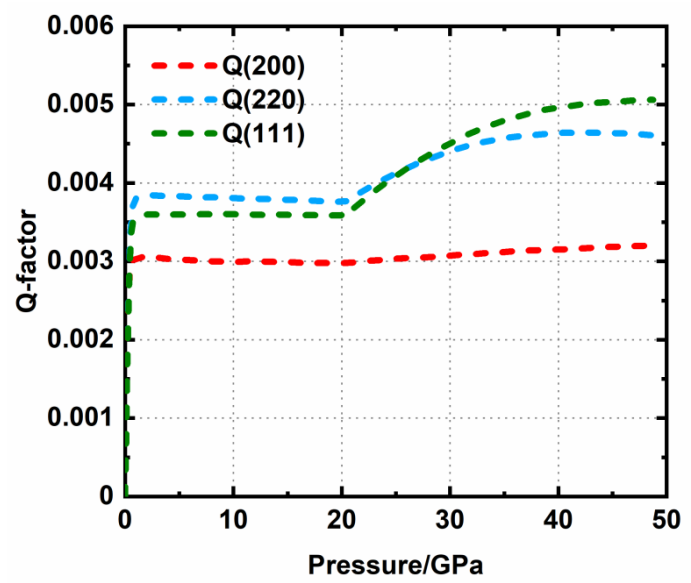

Figure 4. Lattice strains in the EVPSC simulation. Above $20 \mathrm{GPa}, \mathrm{Q}(111)$ gradually surpasses $\mathrm{Q}(220)$ due to "pressure hardening" of $\{100\}\langle 011\rangle$ slip system.

\section{EVPSC}

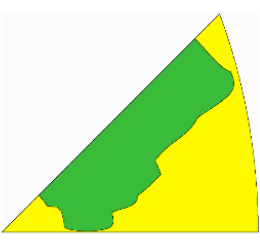

$0 \mathrm{GPa}$

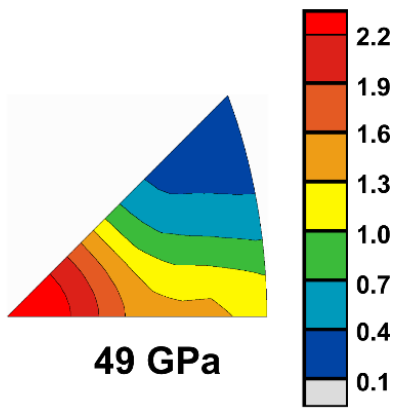

Figure 5. Texture evolution in the EVPSC simulation.

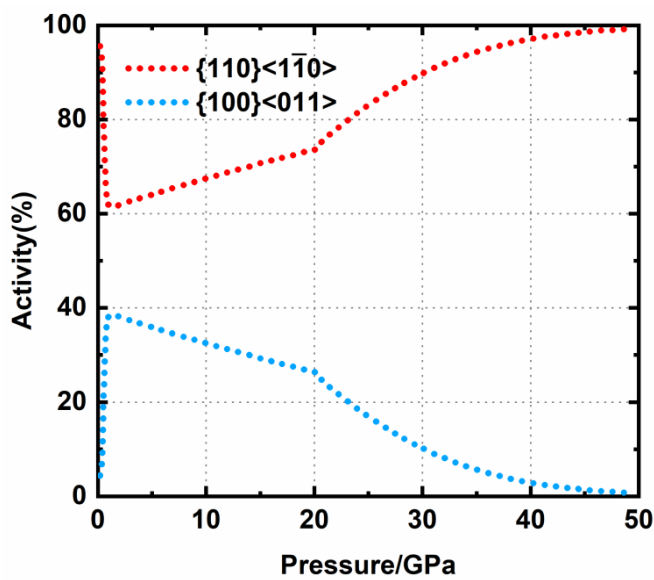

Figure 6. Activity of slip systems in EVPSC simulation. $\{110\}\langle 1 \overline{1} 0\rangle$ and $\{100\}\langle 011\rangle$ slip systems are activated with a ratio of 70:30 and gradually reach 100:0 at $\sim 50 \mathrm{GPa}$. 
The reordering of lattice strains observed in this study is similar to that observed by Marquardt and Miyagi (2015) [36], indicating that this phenomenon is not related to Fe substitution as it is observed both in periclase and ferropericlase. We find that the polycrystal flow strength increases $\sim 25 \%$ due to pressure hardening of the $\{100\}\langle 011\rangle$ slip system (Figure 7). The flow strength measured here is lower compared to previous DAC experiments on periclase [34,45]. This is potentially due to grain-size differences between these experiments [45]. A yield strength increase above $20 \mathrm{GPa}$ is not obvious in [34] since there are only limited data points above 20 GPa. In the work of Singh et al. (2004) [45], there is a jump in measured differential stresses around $20 \mathrm{GPa}$ which may be related to Q(111) crossing $Q(220)$, but individual $Q$ factors were not reported. However, the magnitude of the increase in strength is similar to that observed in this study. Based on these results, $\{110\}\langle 1 \overline{10}\rangle$ slip is increasingly activated with higher pressure. Since previous work has established that $\{100\}\langle 011\rangle$ is more active at higher temperature, temperature and pressure seem to have a competing effect on slip system activities.

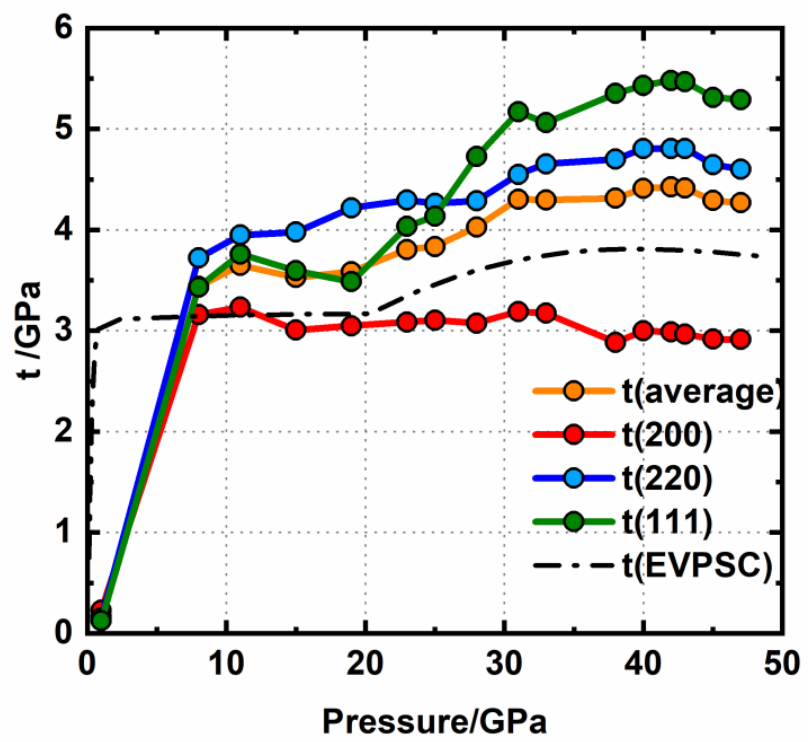

Figure 7. Flow stress of experiment Run 1 calculated using Equation (3) and the EVPSC simulation. Based on the simulation result, the flow stress increases $25 \%$ due to 'pressure hardening' of $\{100\}\langle 011\rangle$ slip system.

It is possible that $\{110\}\langle 1 \overline{1} 0\rangle$ and $\{100\}\langle 011\rangle$ slip systems may have comparable activity at $\mathrm{D}^{\prime \prime}$ conditions. Thus, slip system activity of ferropericlase in a slab that impinges on the CMB boundary could vary as a function of position. If this is the case, $\{100\}\langle 011\rangle$ activity could increase as material moves from cold subduction areas to hot areas adjacent to LLVSPs. Shear wave splitting then should also vary along the slab due to different texture patterns in ferropericlase. In order to provide an observable that can be compared with seismic data, we simulate anisotropy associated with this slip system transition. Texture development is modeled for $100 \%$ simple shear strain with different slip system activities using the Viscoplastic Self Consistent method (VPSC), and shear wave splitting (Figure 8) is calculated using MgO single elastic constant at $125 \mathrm{GPa}$ and $3000 \mathrm{~K}$ from Karki et al. (1999) [46]. When the $\{110\}\langle 1 \overline{10}\rangle$ slip system is dominant, $\mathrm{V}_{\mathrm{SH}}>\mathrm{V}_{\mathrm{SV}}$ splitting should be observed for waves that travel parallel to the CMB (Figure 8), similar to observations in the circum-Pacific. With increasing activity of the $\{100\}\langle 011\rangle$ slip system as temperature increases towards upwelling regions adjacent to LLVSPs, shear wave anisotropy gradually weakens (Figure 8). This is consistent with seismic observations of a weakened anisotropy adjacent to the LLVSP boundary [7,9]. When $\{110\}\langle 1 \overline{1} 0\rangle$ and $\{100\}\langle 011\rangle$ have a similar activity, shear wave anisotropy is weakest, which might be the case at LLVSP boundaries. These simulations of anisotropy associated with a slip system transition in ferropericlase are compatible with seismic observations and provide constraints on the potential contributions of ferropericlase to anisotropy in the deep Earth. The yield strength of ferropericlase is 
also dependent on slip system activities. In addition to the weakening effects of higher temperature, more activation $\{100\}\langle 011\rangle$ slip systems could further decrease the yield strength due to an increase in the degrees of freedom for deformation to occur in the crystal (Figure 7). This may result in a strong yield strength contrast between cold and hot regions. Thus, ferropericlase potentially accommodates more strain adjacent to LLVSPs and contributes more to anisotropy or lack thereof in these regions.

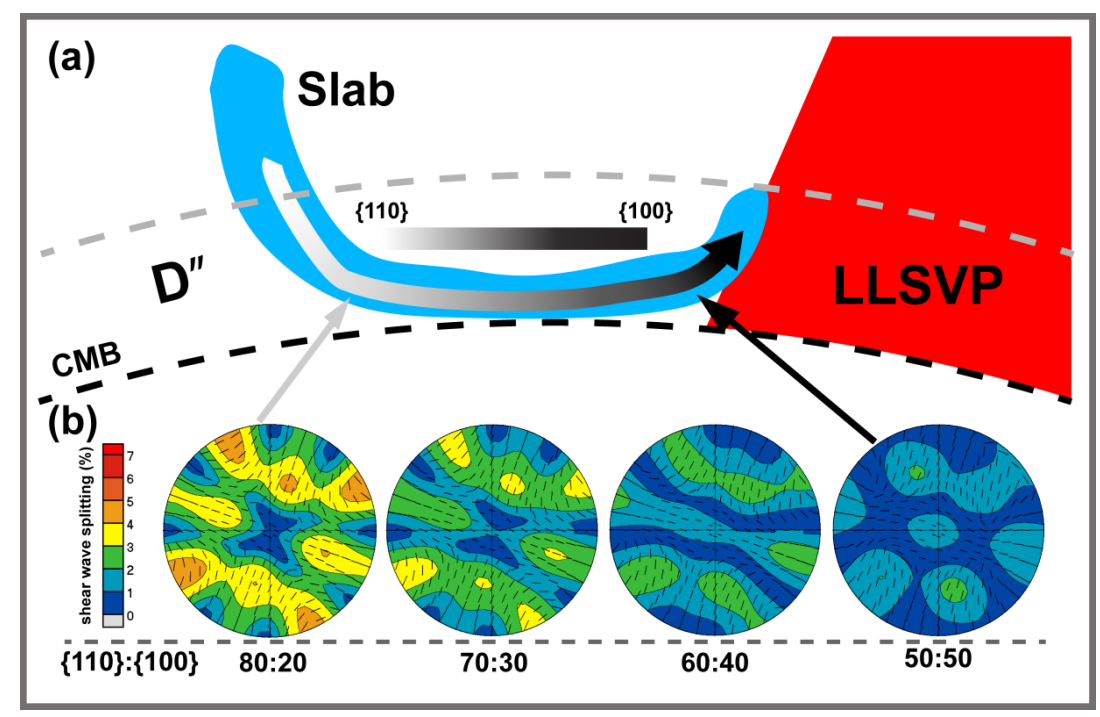

Figure 8. (a) Simplified scheme of a slab sheared along CMB. The greyscale gradient arrow indicates increasing $\{100\}$ activity towards LLVSP. (b) Modeled shear wave anisotropy under $100 \%$ simple shear with different slip system activities. The CMB is horizontal and simple shear is top to the left, parallel to CMB. The black lines indicate the fast shear wave polarization direction. The anisotropy weakens towards the LLVSP due to increasing activity of the $\{100\}$ system.

\section{Conclusions}

In this work, we study the effects of pressure on deformation mechanisms in polycrystalline periclase. We compress samples from ambient conditions up to $50 \mathrm{GPa}$ and record lattice strain and texture evolution. We find an unexpected lattice strain reordering due to a large increase of Q(111) starting at 20 GPa. Similar behavior was previously observed in ferropericlase. We model experimental lattice strains and texture development using the EVPSC method. We find that the $\{110\}\langle 1 \overline{1} 0\rangle$ slip system is increasingly activated above $20 \mathrm{GPa}$ and is fully activated at $\sim 50$ GPa due to "pressure hardening" of the $\{100\}\langle 011\rangle$ slip system. This can explain both texture development and lattice strain reordering. $\{110\}\langle 1 \overline{1} 0\rangle$ slip becomes more favored with higher pressures. Thus, pressure and temperature have a competing effect on the activity of $\{110\}\langle 1 \overline{10}\rangle$ versus $\{100\}\langle 011\rangle$ slip. A transition from a high activity of $\{110\}\langle 1 \overline{1} 0\rangle$ to comparable activation of $\{100\}\langle 011\rangle$ and $\{110\langle 1 \overline{10}\rangle$ in a subducted slab provides an explanation of observed $V_{\mathrm{SH}}>\mathrm{V}_{\mathrm{SV}}$ in the circum-Pacific with a decrease in anisotropy near the margins of LLVSPs.

Author Contributions: Experiment, F.L., S.C., and M.J.; data analysis, F.L.; writing-original draft preparation, F.L.; writing-review and editing, L.M.; supervision, L.M.

Funding: L.M. acknowledges support from the National Science Foundation through EAR-1654687. This work has been supported by the US Department of Energy, National Nuclear Security Administration, through the Capital-DOE Alliance Center (DE-NA0003858), which provided graduate student financial support for M.J. and S.C. as well as support for beamtime.

Acknowledgments: This work was performed at beamline 12.2.2 of the Advanced Light Source. Beamline 12.2.2 at the Advanced Light Source is a DOE Office of Science User Facility under contract no. DE-AC02-05CH11231. This research was partially supported by COMPRES, the Consortium for Materials Properties Research in Earth Sciences under NSF Cooperative Agreement EAR 1606856. We acknowledge Martin Kunz at ALS for technical support. 
Conflicts of Interest: The authors declare no conflict of interest.

\section{References}

1. Meade, C.; Silver, P.G.; Kaneshima, S. Laboratory and seismological observations of lower mantle isotropy. Geophys. Res. Lett. 1995, 22, 1293-1296. [CrossRef]

2. Montagner, J.P.; Kennett, B.L.N. How to reconcile body-wave and normal-mode reference Earth models. Geophys. J. Int. 1996, 125, 229-248. [CrossRef]

3. Panning, M.; Romanowicz, B. A three-dimensional radially anisotropic model of shear velocity in the whole mantle. Geophys. J. Int. 2006, 167, 361-379. [CrossRef]

4. Niu, F.; Perez, A.M. Seismic anisotropy in the lower mantle: A comparison of waveform splitting of SKS and SKKS. Geophys. Res. Lett. 2004, 31. [CrossRef]

5. Lay, T.; Williams, Q.; Garnero, E.J.; Kellogg, L.; Wysession, M.E. Seismic wave anisotropy in the D" region and its implications. Core-Mantle Bound. Reg. 1998, 28, 299-318.

6. Garnero, E.J.; Maupin, V.; Lay, T.; Fouch, M.J. Variable azimuthal anisotropy in Earth's lowermost mantle. Science 2004, 306, 259-261. [CrossRef]

7. Cottaar, S.; Romanowicz, B. Observations of changing anisotropy across the southern margin of the African LLSVP. Geophys. J. Int. 2013, 195, 1184-1195. [CrossRef]

8. Lynner, C.; Long, M.D. Lowermost mantle anisotropy and deformation along the boundary of the African LLSVP. Geophys. Res. Lett. 2014, 41, 3447-3454. [CrossRef]

9. Romanowicz, B.; Wenk, H.R. Anisotropy in the deep Earth. Phys. Earth Planet. Inter. 2017, 269, 58-90. [CrossRef]

10. Merkel, S.; McNamara, A.K.; Kubo, A.; Speziale, S.; Miyagi, L.; Meng, Y.; Duffy, T.; Wenk, H.R. Deformation of $(\mathrm{Mg}, \mathrm{Fe}) \mathrm{SiO} 3$ post-perovskite and D" anisotropy. Science 2007, 316, 1729-1732. [CrossRef]

11. Miyagi, L.; Kanitpanyacharoen, W.; Kaercher, P.; Lee, K.K.; Wenk, H.R. Slip systems in MgSiO3 post-perovskite: Implications for $\mathrm{D}^{\prime \prime}$ anisotropy. Science 2010, 329, 1639-1641. [CrossRef] [PubMed]

12. Nowacki, A.; Wookey, J.; Kendall, J.M. New advances in using seismic anisotropy, mineral physics and geodynamics to understand deformation in the lowermost mantle. J. Geodyn. 2011, 52, 205-228. [CrossRef]

13. Miyagi, L.; Wenk, H.R. Texture development and slip systems in bridgmanite and bridgmanite+ ferropericlase aggregates. Phys. Chem. Miner. 2016, 43, 597-613. [CrossRef]

14. Tsujino, N.; Nishihara, Y.; Yamazaki, D.; Seto, Y.; Higo, Y.; Takahashi, E. Mantle dynamics inferred from the crystallographic preferred orientation of bridgmanite. Nature 2016, 539, 81. [CrossRef] [PubMed]

15. Wenk, H.R.; Speziale, S.; McNamara, A.K.; Garnero, E.J. Modeling lower mantle anisotropy development in a subducting slab. Earth Planet. Sci. Lett. 2006, 245, 302-314. [CrossRef]

16. Wenk, H.R.; Cottaar, S.; Tomé, C.N.; McNamara, A.; Romanowicz, B. Deformation in the lowermost mantle: From polycrystal plasticity to seismic anisotropy. Earth Planet. Sci. Lett. 2011, 306, 33-45. [CrossRef]

17. Walker, A.M.; Forte, A.M.; Wookey, J.; Nowacki, A.; Kendall, J.M. Elastic anisotropy of D" predicted from global models of mantle flow. Geochem. Geophys. Geosyst. 2011, 12. [CrossRef]

18. Cottaar, S.; Li, M.; McNamara, A.K.; Romanowicz, B.; Wenk, H.R. Synthetic seismic anisotropy models within a slab impinging on the core-mantle boundary. Geophys. J. Int. 2014, 199, 164-177. [CrossRef]

19. Girard, J.; Amulele, G.; Farla, R.; Mohiuddin, A.; Karato, S.I. Shear deformation of bridgmanite and magnesiowüstite aggregates at lower mantle conditions. Science 2016, 351, 144-147. [CrossRef]

20. Marquardt, H.; Speziale, S.; Reichmann, H.J.; Frost, D.J.; Schilling, F.R.; Garnero, E.J. Elastic shear anisotropy of ferropericlase in Earth's lower mantle. Science 2009, 324, 224-226. [CrossRef]

21. Finkelstein, G.J.; Jackson, J.M.; Said, A.; Alatas, A.; Leu, B.M.; Sturhahn, W.; Toellner, T.S. Strongly Anisotropic Magnesiowüstite in Earth's Lower Mantle. J. Geophys. Res. Solid Earth 2018, 123, 4740-4750. [CrossRef]

22. Amodeo, J.; Merkel, S.; Tromas, C.; Carrez, P.; Korte-Kerzel, S.; Cordier, P.; Chevalier, J. Dislocations and Plastic Deformation in MgO Crystals: A Review. Crystals 2018, 8, 240. [CrossRef]

23. Copley, S.M.; Pask, J.A. Plastic deformation of MgO single crystals up to 1600 C. J. Am. Ceram. Soc. 1965, 48, 139-146. [CrossRef]

24. Hulse, C.O.; Copley, S.M.; Pask, J.A. Effect of crystal orientation on plastic deformation of magnesium oxide. J. Am. Ceram. Soc. 1963, 46, 317-323. [CrossRef] 
25. Paterson, M.S.; Weaver, C.W. Deformation of polycrystalline MgO under pressure. J. Am. Ceram. Soc. 1970, 53, 463-471. [CrossRef]

26. Sato, F.; Sumino, K. The yield strength and dynamic behavior of dislocations in $\mathrm{MgO}$ crystals at high temperatures. J. Mater. Sci. 1980, 15, 1625-1634. [CrossRef]

27. Barthel, C. Plastiche Anisotropie von Bleisulfid und Magnesiumoxid; University of Gottingen: Gottingen, Germany, 1984.

28. Appel, F.; Wielke, B. Low temperature deformation of impure MgO single crystals. Mater. Sci. Eng. 1985, 73, 97-103. [CrossRef]

29. Stretton, I.; Heidelbach, F.; Mackwell, S.; Langenhorst, F. Dislocation creep of magnesiowüstite (Mg0. $8 \mathrm{Fe} 0$. 2O). Earth Planet. Sci. Lett. 2001, 194, 229-240. [CrossRef]

30. Amodeo, J.; Carrez, P.; Cordier, P. Modelling the effect of pressure on the critical shear stress of $\mathrm{MgO}$ single crystals. Philos. Mag. 2012, 92, 1523-1541. [CrossRef]

31. Carrez, P.; Ferré, D.; Cordier, P. Peierls-Nabarro modelling of dislocations in MgO from ambient pressure to 100 GPa. Model. Simul. Mater. Sci. Eng. 2009, 17, 035010. [CrossRef]

32. Girard, J.; Chen, J.; Raterron, P. Deformation of periclase single crystals at high pressure and temperature: Quantification of the effect of pressure on slip-system activities. J. Appl. Phys. 2012, 111, 112607. [CrossRef]

33. Lin, F.; Hilairet, N.; Raterron, P.; Addad, A.; Immoor, J.; Marquardt, H.; Tomé, C.N.; Miyagi, L.; Merkel, S. Elasto-viscoplastic self consistent modeling of the ambient temperature plastic behavior of periclase deformed up to 5.4 GPa. J. Appl. Phys. 2017, 122, 205902. [CrossRef]

34. Merkel, S.; Wenk, H.R.; Shu, J.; Shen, G.; Gillet, P.; Mao, H.K.; Hemley, R.J. Deformation of polycrystalline $\mathrm{MgO}$ at pressures of the lower mantle. J. Geophys. Res. Solid Earth 2002, 107, ECV-3. [CrossRef]

35. Lin, J.F.; Wenk, H.R.; Voltolini, M.; Speziale, S.; Shu, J.; Duffy, T.S. Deformation of lower-mantle ferropericlase $(\mathrm{Mg}, \mathrm{Fe}) \mathrm{O}$ across the electronic spin transition. Phys. Chem. Miner. 2009, 36, 585. [CrossRef]

36. Marquardt, H.; Miyagi, L. Slab stagnation in the shallow lower mantle linked to an increase in mantle viscosity. Nat. Geosci. 2015, 8, 311. [CrossRef]

37. Immoor, J.; Marquardt, H.; Miyagi, L.; Lin, F.; Speziale, S.; Merkel, S.; Buchen, J.; Kurnosov, A.; Liermann, H.P. Evidence for $\{100\}<011>$ slip in ferropericlase in Earth's lower mantle from high-pressure/high-temperature experiments. Earth Planet. Sci. Lett. 2018, 489, 251-257. [CrossRef]

38. Merkel, S.; Yagi, T. X-ray transparent gasket for diamond anvil cell high pressure experiments. Rev. Sci. Instrum. 2005, 76, 046109. [CrossRef]

39. Singh, A.K. The lattice strains in a specimen (cubic system) compressed nonhydrostatically in an opposed anvil device. J. Appl. Phys. 1993, 73, 4278-4286. [CrossRef]

40. Zha, C.S.; Mao, H.K.; Hemley, R.J. Elasticity of $\mathrm{MgO}$ and a primary pressure scale to 55 GPa. Proc. Natl. Acad. Sci. USA 2000, 97, 13494-13499. [CrossRef]

41. Lutterotti, L.; Matthies, S.; Wenk, H.R.; Schultz, A.S.; Richardson, J.W., Jr. Combined texture and structure analysis of deformed limestone from time-of-flight neutron diffraction spectra. J. Appl. Phys. 1997, 81, 594-600. [CrossRef]

42. Wenk, H.R.; Lutterotti, L.; Kaercher, P.; Kanitpanyacharoen, W.; Miyagi, L.; Vasin, R. Rietveld texture analysis from synchrotron diffraction images. II. Complex multiphase materials and diamond anvil cell experiments. Powder Diffr. 2014, 29, 220-232. [CrossRef]

43. Wang, H.; Wu, P.D.; Tomé, C.N.; Huang, Y. A finite strain elastic-viscoplastic self-consistent model for polycrystalline materials. J. Mech. Phys. Solids 2010, 58, 594-612. [CrossRef]

44. Amodeo, J.; Dancette, S.; Delannay, L. Atomistically-informed crystal plasticity in MgO polycrystals under pressure. Int. J. Plast. 2016, 82, 177-191. [CrossRef]

45. Singh, A.K.; Liermann, H.P.; Saxena, S.K. Strength of magnesium oxide under high pressure: Evidence for the grain-size dependence. Solid State Commun. 2004, 132, 795-798. [CrossRef]

46. Karki, B.B.; Wentzcovitch, R.D.; De Gironcoli, S.; Baroni, S. First-principles determination of elastic anisotropy and wave velocities of $\mathrm{MgO}$ at lower mantle conditions. Science 1999, 286, 1705-1707. [CrossRef]

(C) 2019 by the authors. Licensee MDPI, Basel, Switzerland. This article is an open access article distributed under the terms and conditions of the Creative Commons Attribution (CC BY) license (http://creativecommons.org/licenses/by/4.0/). 